\title{
Composite Façade Elements with Self-Cleaning Surface made of Ultra- High-Performance Concrete (UHPC)
}

\author{
Julia von Werder ${ }^{1}$, Patrick Fontana ${ }^{2}$, Johannes Hoppe ${ }^{1}$, Serdar Bilgin $^{3}$ and Birgit Meng ${ }^{1}$ \\ ${ }^{1}$ Bundesanstalt für Materialforschung und -prüfung (BAM), Unter den Eichen 87, 12205 Berlin, \\ Germany, julia.von-werder@bam.de \\ ${ }^{2}$ RISE Research Institutes of Sweden, Division Built Environment, Drottning Kristinas väg 26, 11428 \\ Stockholm, Sweden, Patrick.fontana@ri.se \\ ${ }^{3}$ Deutscher Beton- und Bautechnik-Verein E.V., Kurfürstenstraße 129, 10785 Berlin, \\ Bilgin@betonverein.de
}

\begin{abstract}
In the framework of the European project H-House various concrete façade elements were developed with the aim to ensure a long service life by combining a very durable material with selfcleaning properties. The façade elements presented are made of a shell of UHPC filled with blocks of aerated autoclaved concrete as insulating material. Self-cleaning properties were realized amongst others by imprinting a microstructure into the surface during casting. The paper focuses on selected technological aspects of the manufacturing process of prototypes which had to be performed in two concreting sections. Furthermore the challenges faced when upscaling the self-cleaning properties are addressed and the strategy to assess the self-cleaning properties by measuring the contact and the rolloff angel is presented. The results show that a successfull upscalaing process requires detailed planning and that the best results can often be achieved with a moderate work effort or material use.
\end{abstract}

Keywords: Ultra-High-Performance Concrete, Façade Elements, Self-Cleaning Properties, Adhesive Pull-Strength, Microstructure, Architectural Concrete.

\section{Introduction}

Highly automated production plants and design methods based on Building Information Modelling (BIM) make the prefabrication of building elements very efficient. Façade elements made from concrete can be produced regardless of weather conditions in variable shapes and at the highest quality and delivered just in time to the building site. Aim of the European project $[\mathrm{H}]$ house (Healthier Life with Eco-innovative Components for housing Constructions) was to develop a variety of new multifunctional and flexible building components which are characterized by long service life, reduced maintenance and a long-term improvement of energy efficiency. Within the project part the BAM was involved, self-supporting sandwich façade elements consisting of a thin shell of ultra-high performance concrete (UHPC) filled with an insulation of autoclaved aerated concrete (AAC) were designed (Miccoli et al., 2015, Fontana et al., 2016). UHPC allows the manufacture of very filigree, lightweight and resource-efficient building components with high durability and is therefore optimally suited for pre-fabrication. Sustainability of the façade elements was further increased by the optimization of the binder and adding self-cleaning properties to the surface based on either the integration of photocatalytic $\mathrm{TiO}_{2}$ into the bulk of the thin UHPC layer or by copying the Lotus ${ }^{\circledR}$ effect. Selfcleaning properties referred to as the Lotus ${ }^{\circledR}$ effect are based on the interaction of the specific micro texture and the water-repellent nature of the surface that makes a water droplet taking off 
pollutions from the surface when it is rolling off (Barthlott et al., 2016, Si et al., 2018)

\section{Materials and Methods}

The concrete mixture specified in Table 1 was designed by the company Dyckerhoff which was one of the industrial project partners. While ensuring a minimum strength requirement of 100 MPa a binder composition named [H] house Compound 5941 based on the Nanodur ${ }^{\circledR}$ fine mix was developed which contains less than $55 \%$ Portland cement clinker and results in a reduction of non-renewable energy and global warming potential (Deuse et al., 2018).

Table 1. UHPC mixture.

\begin{tabular}{cc}
\hline Material & Content in $\mathrm{kg} / \mathrm{m}^{3}$ \\
\hline$[\mathrm{H}]$ house Compound 5941 grey & 1050 \\
\hline Aggregate (0-2 $\mathrm{mm})$ & 1150 \\
\hline PCE superplasticizer & 17,85 \\
\hline Water & 178,5 \\
\hline
\end{tabular}

Due to its fineness and fine-tuned granulometry the mixture further allows to imprint a microstructure into the concrete surface with very high quality. Figure 1 shows confocal laser images of a technical fabric with a defined micro texture that was used as substrate for the UHPC cast (a) and the resulting UHPC surface (b), which demonstrate the very accurate and

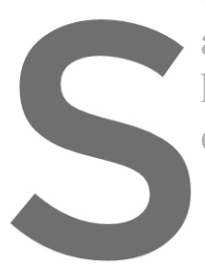
almost defect-free replication hydrophobic surface concreting and incorp
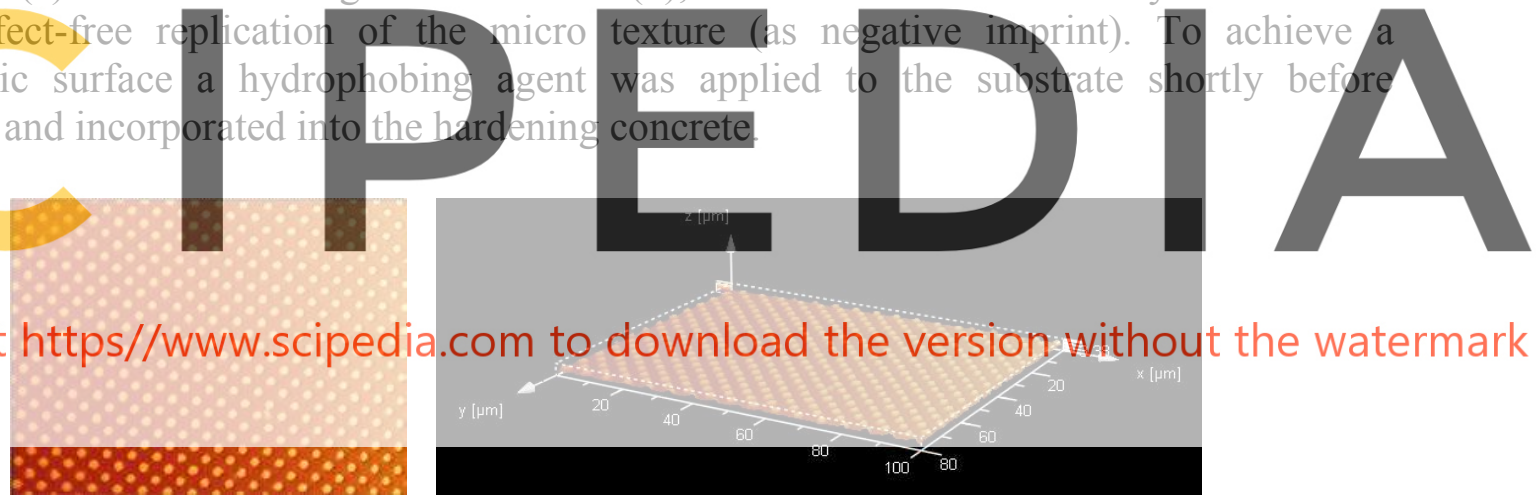

a. Substrate with 'pimples' (diameter: $3 \mu \mathrm{m}$ )
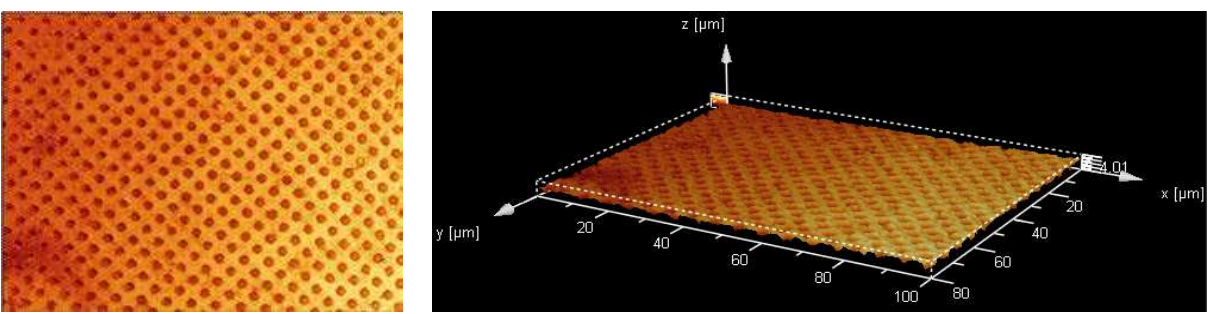

b. UHPC cast with holes (diameter: $3 \mu \mathrm{m}$ )

Figure 1. Confocal laser images of substrate (a) and UHPC surface (b).

Based on structural and economic reasons the façade panels are designed as box shaped UHPC elements which are protecting the shock sensitive AAC insulation (Figure 2). Due to the 
support from the edges of the box no shear forces are generated in the interface between load bearing structure and insulation during transport and service life so that additional connectors can be omitted. The frame further increases the stiffness of the box-shaped element so that the cross-section of the UHPC can be decreased. When casting the elements with a single concrete batch the floating body had to be protected against buoyancy which was discarded because of its proneness to errors. Therefore, the façade elements were manufactured in two steps. After initial hardening of the exterior layer a rigid frame was placed as internal formwork on top of the panel and the upturning edges of the box were cast in a second concreting section.

In the following sections selected tests regarding different technological aspects during the upscaling process are presented. They concern the analysis of the bond strength between the two concreting sections, the optimization of imprinting a microstructure with a hydrophobic surface and the assessment of the homogeneity of the self-cleaning surface.
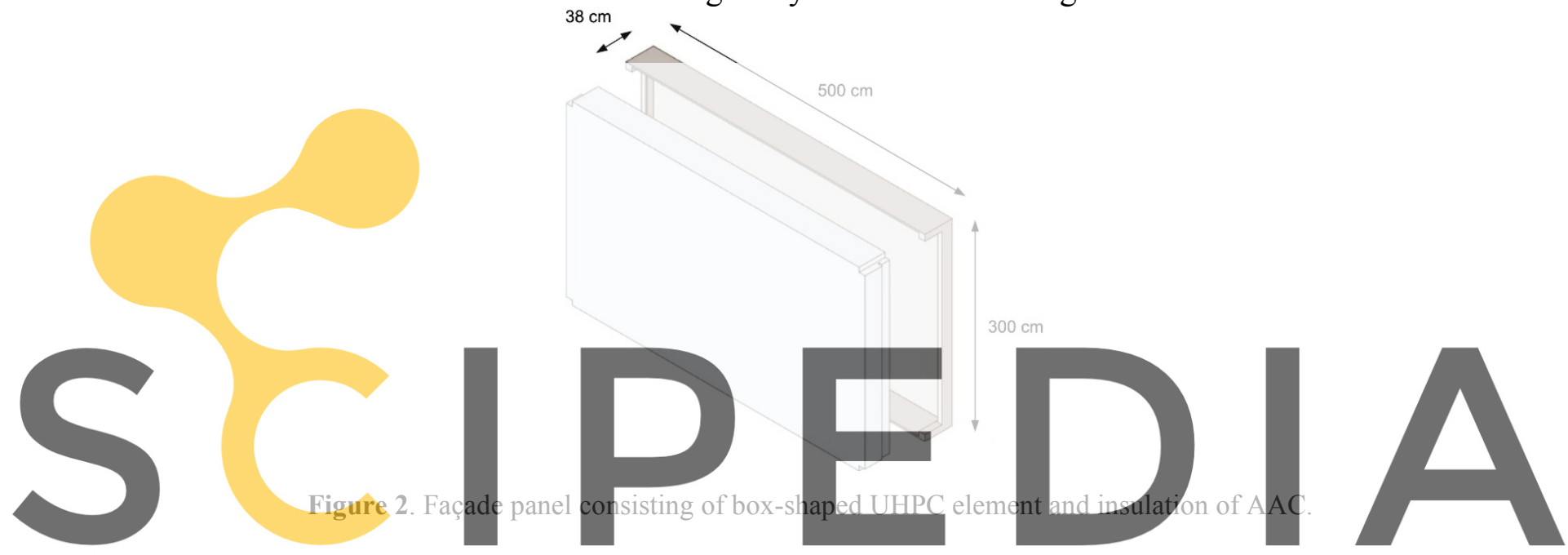

\section{Technological Aspects}

Register for free at https//www.scipedia.com to download the version without the watermark 3.1 Adhesive Pull Strength between the Two Concreting Sections

To identify the best surface treatment for an optimum bond between the two concreting sections adhesive pull strength tests were performed at samples sized $30 \times 30 \mathrm{~cm}$ which were manufactured in wooden formwork coated with a plastic film. After the final setting of the first $2,5 \mathrm{~cm}$ thick concreting layer the surface was either left untouched, wetted or roughened using a wire brush (b) in one (1d) or two directions (2d) before the second layer with a thickness of $7,5 \mathrm{~cm}$ was poured (Figure 3). After an aeration time of 5 minutes the samples were covered until stripping after 18 hours. The samples were turned around so that the first thinner layer was on the top and the adhesive pull strength was tested according to DIN EN 1542. The surface tensile strength of the monolithic system served as reference. In addition, the effect of a bonding coat $(\mathrm{BC})$ applied to the first layer before concreting the second layer was included into the examination.

The results of the adhesive pull strength (Figure 4) illustrate that without roughening the surface the bond strength between the two concreting sections is only about $12 \%$ of the surface bond strength of the reference sample and wetting of the surface only has a negligible effect. 


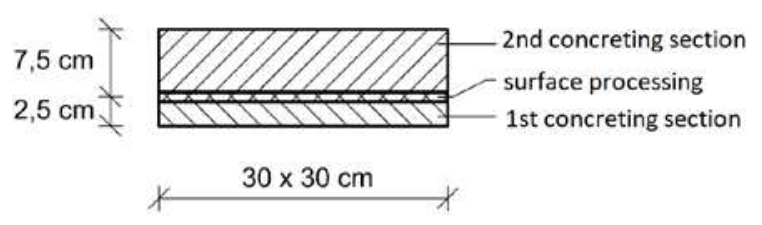

Figure 3. Sample for testing adhesive strength.

Within the "elephant skin" which formed on the first layer ventilation pores are trapped and weaken the cross section (Figure 5, left). After roughening the surface with a steel brush in one direction the loadbearing behavior corresponds to the monolithic reference so that no further measures are necessary. The system fails not in the joint but within the second layer, which was concreted several hours later than the first layer. The application of a bonding coat in contrast lead to an early cohesion failure within the bonding coat.
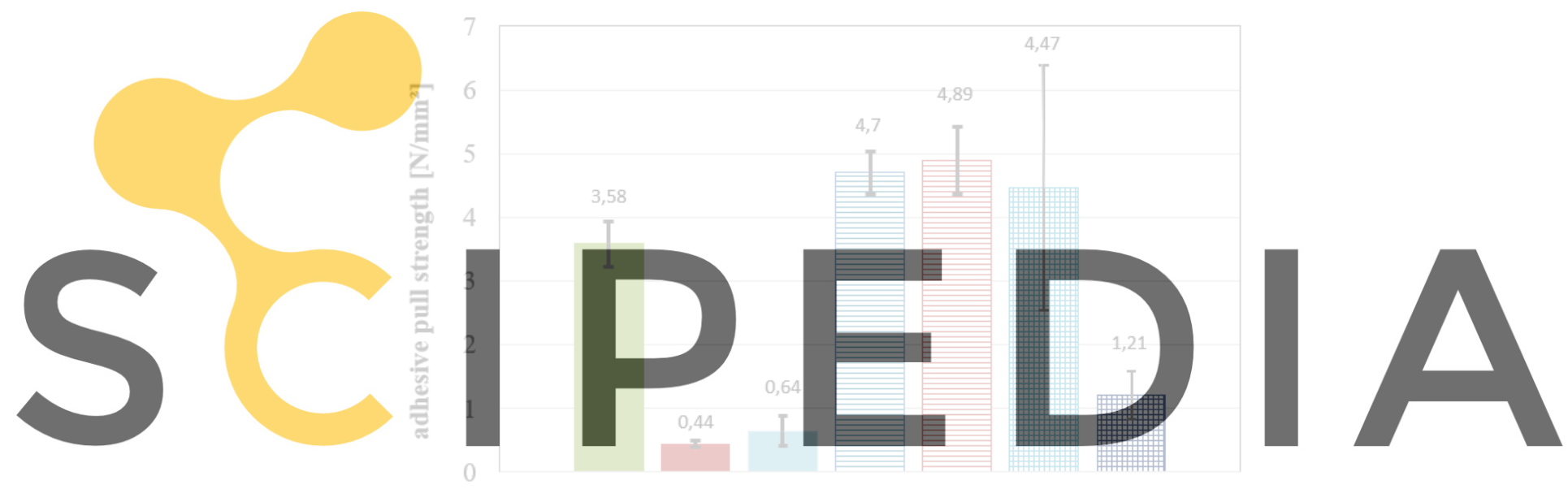

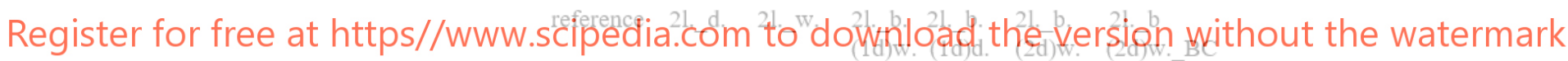

Figure 4. Surface (reference) and adhesive pull strength depending on the processing of the surface before concreting the second layer. $2 \mathrm{l}=$ two layers, $\mathrm{b}=$ brush, $\mathrm{d}=$ dry, $\mathrm{w}=$ wet, $\mathrm{BC}=$ bonding coat.
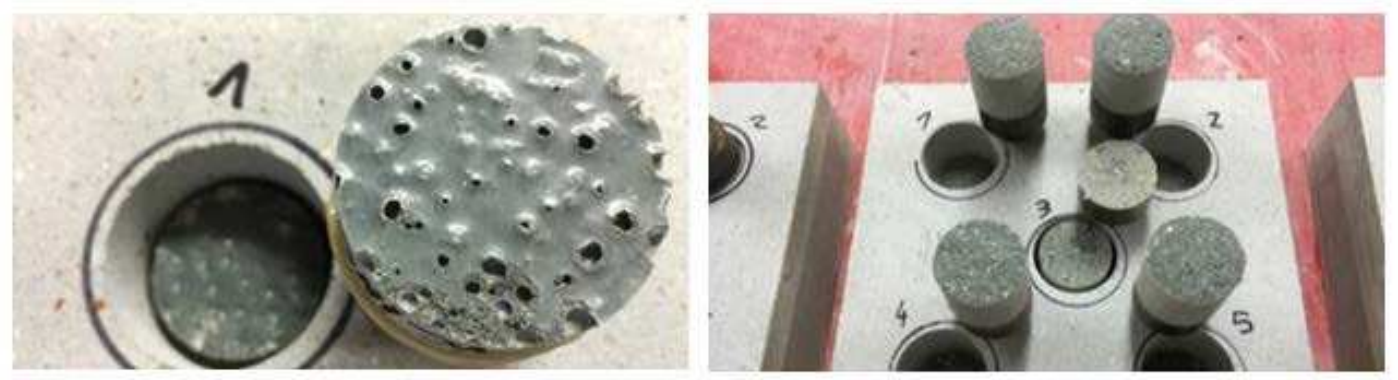

Figure 5. Failure in the joint due to "elephant skin" (left) and cohesion failure within the 2nd layer (right). 


\subsection{Upscaling of Micro Structured Self-Cleaning Surfaces}

For the manufacture of the micro structured surfaces formliners covered with a hydrophobing or releasing agent were integrated into the formwork. In a first step different substrates were analyzed regarding the durability of the surface quality and the hydrophobic properties of the concrete specimens cast in them. For this, measurements of roughness, contact and roll-off angle, lightness and proportion of pores were performed over the course of ten consecutive pours using the same formwork. The root mean squared roughness was measured with a confocal laser microscope and the contact and roll-off angle were determined with a contact angle measuring system. The lightness and the proportion of pores were calculated using a color calibrated scanner whereby the value 255 corresponds to white. Best results were achieved for a substrate of polyurethane rubber to which $80 \mathrm{~g} / \mathrm{m}^{2}$ of hydrophobing agent based on silane and siloxane were applied before the concreting.

All the parameters measured for evaluating the stability of the surface quality for both substrate and concrete exhibit only minor changes over the course of the pours (Figure 6). The contact angle measured on the formliner when using the hydrophobing agent as test liquid is always far below $90^{\circ}$ ensuring a homogeneous wetting of the substrate. The contact angles of the concrete surfaces in contrast stay always over $140^{\circ}$ and are thereby attaining superhydrophobic properties. The slope angels of the concrete samples cast remain very small throughout the repeated use of the formwork ensuring very good self-cleaning properties. The lightness of the surface does not decrease and the proportion of pores is always below $0,9 \%$
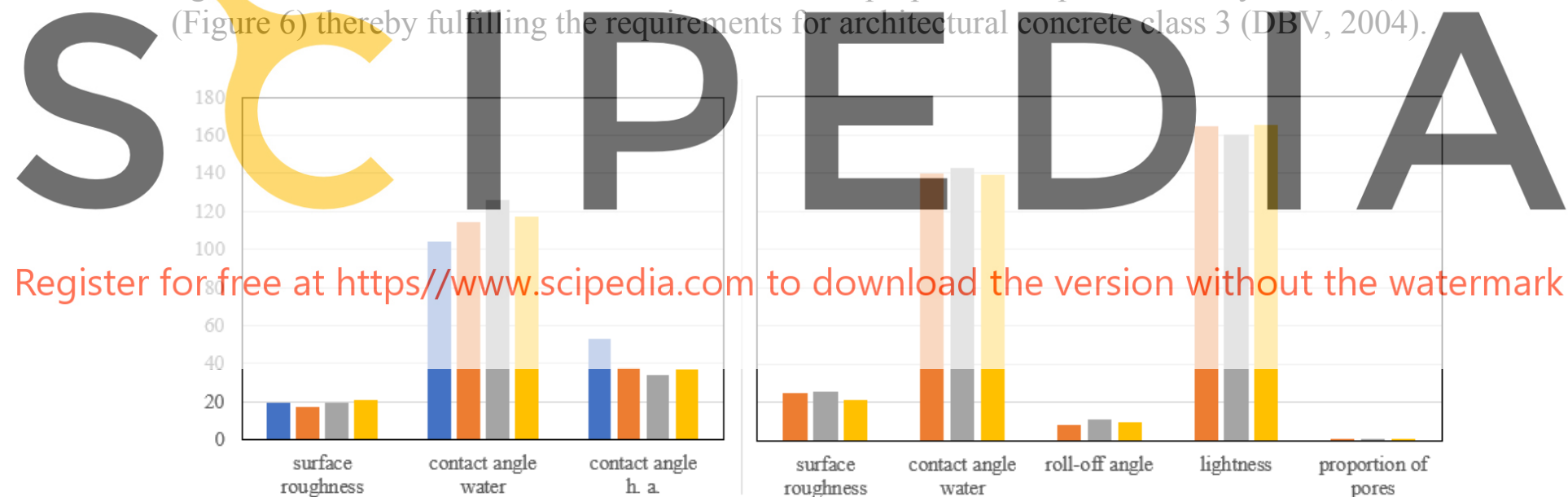

Register forfree at https//www.scipedia.com to download the version without the watermark

Figure 6. Parameters evaluated for the substrate and the UHPC sample during subsequent concreting.

In a second study the impact of the time span between application of the hydrophobing agent and the concreting was examined in detail using the following test set-up: Ten frame formworks sized $10 \times 10 \mathrm{~cm}$ were positioned on a micro-structured silicone mat, to which $90 \mathrm{~g} / \mathrm{m}^{2}(45 \mathrm{~g}$ of active ingredient) of the hydrophobing agent was applied with a brush. After continuously increasing time intervals the formwork was filled with concrete and after 5 minutes of deaeration covered with plastic sheets for curing. To analyze the evaporated amount of hydrophobing agent in the time span between application and concreting a reference formwork consisting of frame and silicone mat with the equal amount of hydrophobing agent was weighed in the corresponding time intervals. 
After stripping the formwork, the concrete surface was assessed visually and by measuring the contact and the roll-off angel (Figure 7).

The results show that even after a time span of 90 minutes between application of the hydrophobing agent and concreting the UHPC surface can be called superhydrophobic. While the contact angel remains on the original level, the slope angel after 30 minutes increases discontinuously from 5 to $37^{\circ}$ (Figure 7). The quality of the architectural concrete however deteriorates when the time span between application of the hydrophobing agent and concreting exceeds 10 minutes (Figure 8).

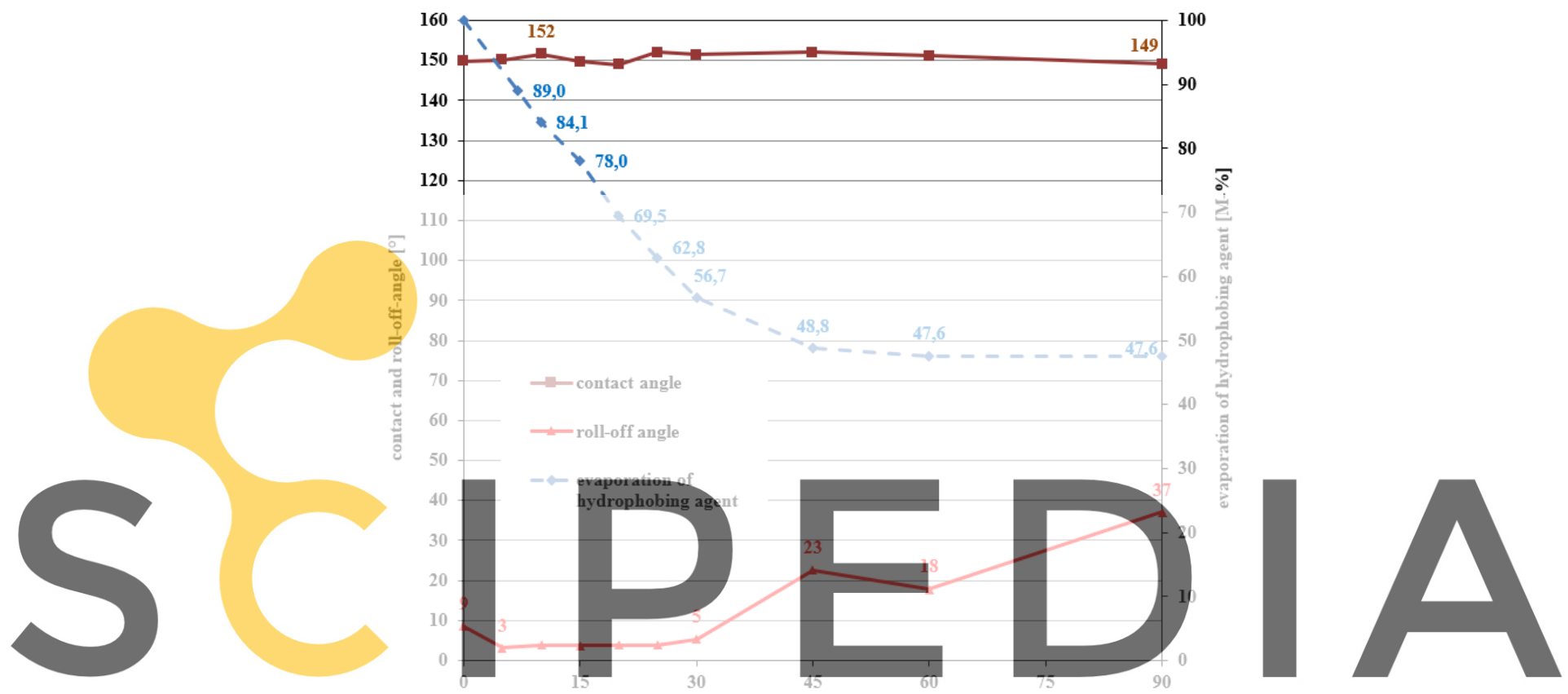

time span between application of hydrophobing agent and concreting [min] application of the hydrophobing agent and concreting.
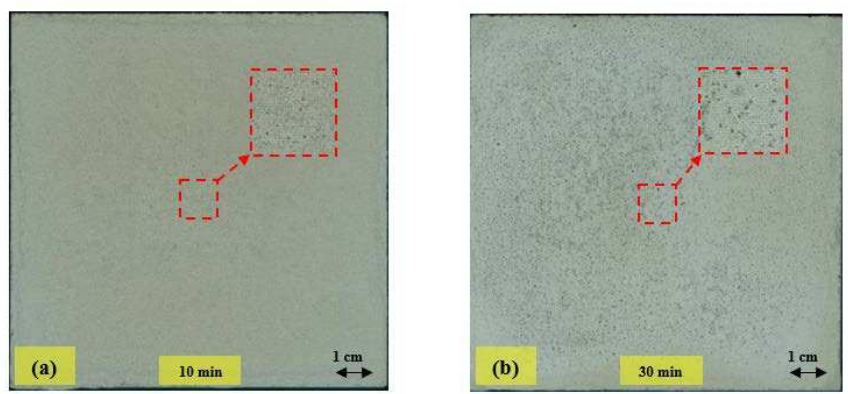

Figure 8. Quality of architectural concrete gained after (a) $10 \mathrm{~min}$ and (b) $30 \mathrm{~min}$ time span between application of the hydrophobing agent and concreting.

In a further step the impact of the application of the hydrophobing agent and the flow behavior on the hydrophobicity of the concrete surface was assessed by concreting samples sized $160 \times 60 \mathrm{~cm}$. Within the test series the hydrophobing agent was applied in different 
amounts $160 \mathrm{~g} / \mathrm{m}^{2}$ and $80 \mathrm{~g} / \mathrm{m}^{2}$ (active ingredient content $80 \mathrm{~g} / \mathrm{m}^{2}$ and $40 \mathrm{~g} / \mathrm{m}^{2}$ ) and dilution with water (1:1, none) to the silicon mat at the bottom of the formwork in two different ways (spray and roller application). Maximum 5 minutes after the application of the hydrophobing agent the concrete was cast using a conical discharge hopper positioned $40 \mathrm{~cm}$ from the rim of the formwork (Figure 9, left). The formwork was stripped after 24 hours and the elements were stored for 14 days at $23^{\circ} \mathrm{C}$ and $50 \mathrm{RH}$. Afterwards 11 cores with a diameter of $10 \mathrm{~cm}$ were drilled out of the element (Figure 9, right) and after cleaning with rinsing water stored for another week at $23{ }^{\circ} \mathrm{C}$ and $50 \mathrm{RH}$ before the contact and slope angles were measured.

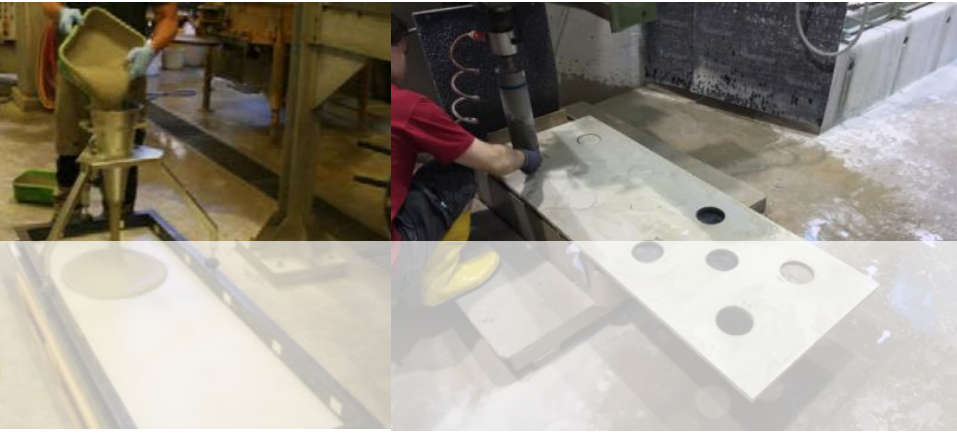

Figure 9. Concreting of test samples (left) and core extractions (right) to assess the self-cleaning properties.
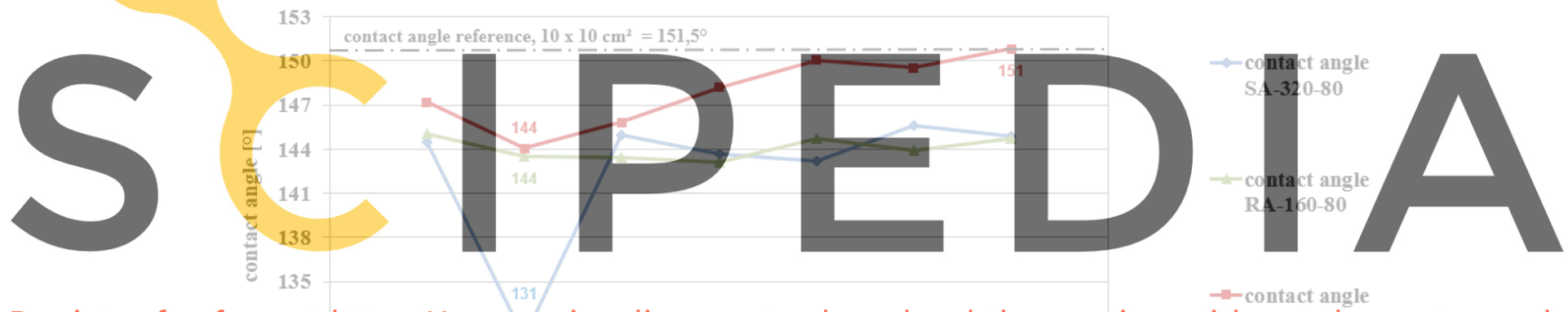

Register for free1zt https//www.Scipedia.com to download the version withøettuthe watermark

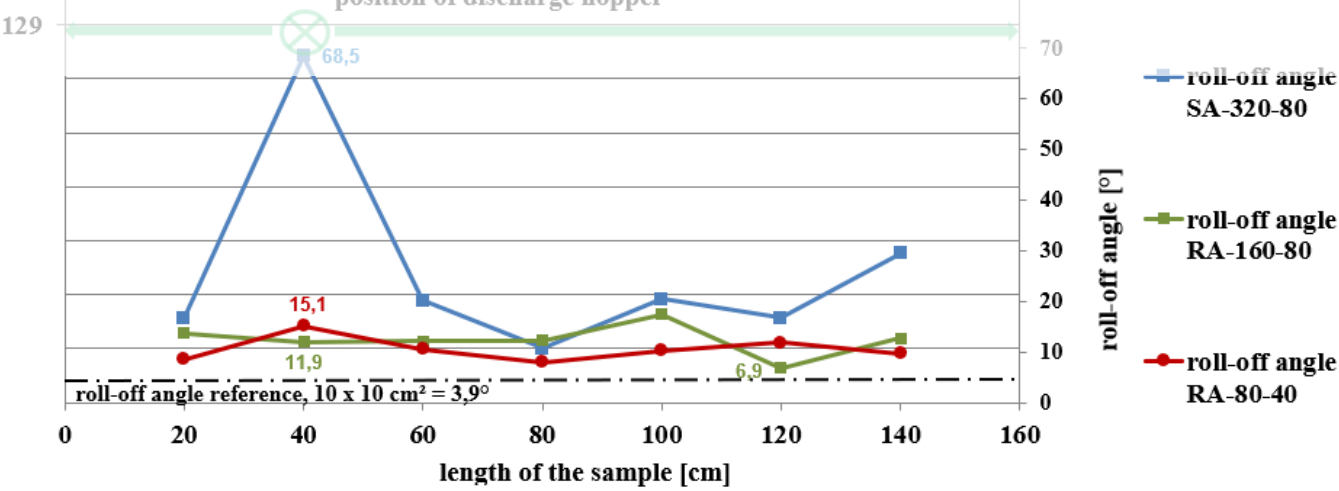

Figure 10. Hydrophobic quality of the surface depending on the distance from the discharge hopper. SA $=$ spray application, RA = roller application; numbers define amount of application / active ingredient $\left[\mathrm{g} / \mathrm{m}^{2}\right]$.

The assessment of the hydrophobic quality (Figure 10) illustrates that the application of a bigger amount of hydrophobing agent diluted in the proportion of 1:1 with water leads to a strong increase of the hydrophobic surface quality at the discharge hopper (blue curve). For the small amount of hydrophobing agent applied undiluted to the silicon mat in contrast only a 
small decrease of the contact angle was measured at the position of the discharge hopper (red curve). With increasing distance from the location of pouring the contact angle increased. The specimen further showed the smallest and most homogeneous sliding angels.

\section{Conclusions}

- The results show that upscaling the production of the façade elements needs detailed planning in order to achieve architectural concrete with self-cleaning properties. The highest bond strength between the two concreting sections is achieved by roughening the surface of the first section with a wire brush. An additional wetting of the surface deteriorates rather than improves the adhesive pull strength between the concreting sections. Also, for the application of the hydrophobing agent it turned out that less is more. The best results regarding the homogeneity of the self-cleaning properties were measured for the application of the smallest amount of hydrophobing agent using a brush.

- The time span between application of the hydrophobing agent and concreting is limited due to the decrease in quality of the architectural concrete.

\section{Acknowledgements}

The authors thank Paul Schwer for conducting some of the experiments and the European Union for the grant agreement no. 608893 (H-House) within the European Union's Seventh Framework Programme.

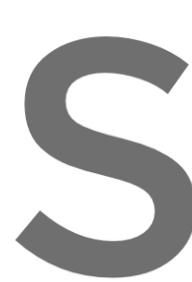

ORCID
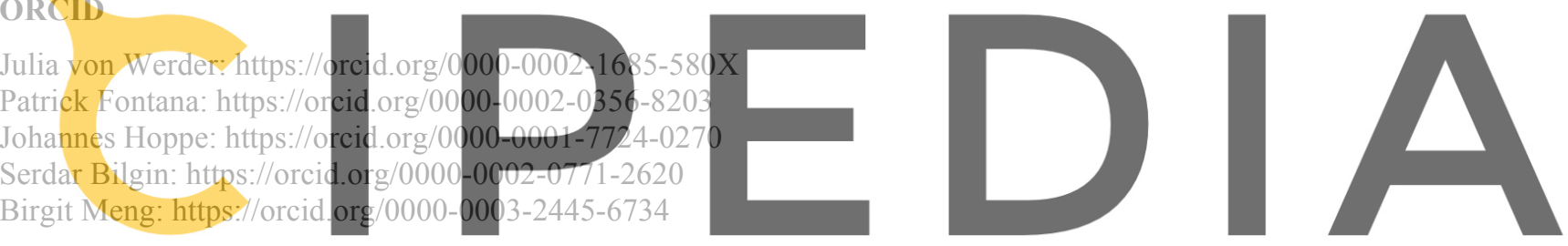

References

Register for free at https//www scipedia.com to download the version without the watermark Evolution, Structural Principles and Biomimetic Applications. Philos. Trans. R. Soc., A 2016, 374, doi: 10.1098/rsta.2016.0191

Deuse, T., Mutke, S., Parker, F., Qvaeschning D. and Wulff, M. (2018). Nanotechnically optimized binders for the production of user-friendly high-performance concrete-part 1, Cement International 1/18, Vol. 16, 59-69

Deuse, T., Mutke, S., Parker, F., Qvaeschning D. and Wulff, M. (2018). Nanotechnically optimized binders for the production of user-friendly high-performance concrete-part 2, Cement International 5/18, Vol. 16, 12-22

Deutscher Beton- and Bautechnik-Verein E.V. (DBV), Verein Deutscher Zementwerke E.V. (VDZ) (2004). Merkblätter, Deutscher Beton- und Bautechnik-Verein E.V., Bauausführung, Sichtbeton Exposed Concrete, Berlin / Düsseldorf

DIN EN 1542: 1999-07: Products and systems for the protection and repair of concrete structures - Test methods Measurement of bond strength by pull-off

Fontana, P., Miccoli, L., Kocadag, R., Silva, N., Qvaeschning, D., Kreft, O. and Cederquvist, C. (2016). Composite UHPC façade elements with functional surfaces, HiPerMat 2016, Kassel, Germany, March 9-11

Miccoli, L., Fontana, P, Silva, N., Klinge, A., Cederqvist, C., Kreft, O., Qvaeschning, D. and Sjöstrom, C. (2015). Composite UHPC-AAC/CLC facade elements with modified interior plaster for new buildings and refurbishment. Materials and production technology, Journal of Facade Design and Engineering 3, 91-102, doi: 10.3233/FDE-150029

Si, Y., Dong, Z. and Jiang, L. (2018) Bioinspired Designs of Superhydrophobic and Superhydrophilic Materials, ACS Cent. Sci. 2018, 4, 9, 1102-1112, doi: 10.1021/acscentsci.8b00504 